OPEN ACCESS

Edited by:

Christopher Robert McCurdy, University of Florida, United States

Reviewed by: Lance R. McMahon, University of Florida, United States Sara Jane Ward, Temple University, United States

*Correspondence: Zurina Hassan zurina_hassan@usm.my Christian P. Müller Christian.Mueller@uk-erlangen.de

Specialty section: This article was submitted to Experimental Pharmacology and Drug

Discovery,

a section of the journal Frontiers in Pharmacology

Received: 11 May 2021 Accepted: 29 June 2021 Published: 12 July 2021

Citation: Hassan R, Sreenivasan S, Müller CP and Hassan Z (2021) Methadone,

Buprenorphine, and Clonidine Attenuate Mitragynine Withdrawal

in Rats.

Front. Pharmacol. 12:708019. doi: 10.3389/fphar.2021.708019

\section{Methadone, Buprenorphine, and Clonidine Attenuate Mitragynine Withdrawal in Rats}

\author{
Rahimah Hassan ${ }^{1}$, Sasidharan Sreenivasan ${ }^{2}$, Christian P. Müller ${ }^{1,3 *}$ and Zurina Hassan ${ }^{1,4 *}$ \\ ${ }^{1}$ Centre for Drug Research, Universiti Sains Malaysia, Minden, Malaysia, ${ }^{2}$ Institute for Research in Molecular Medicine, Universiti \\ Sains Malaysia, Minden, Malaysia, ${ }^{3}$ Section of Addiction Medicine, Department of Psychiatry and Psychotherapy, University \\ Clinic, Friedrich-Alexander-University Erlangen-Nuremberg, Erlangen, Germany, ${ }^{4}$ Addiction Behaviour and Neuroplasticity \\ Laboratory, National Neuroscience Institute, Singapore, Singapore
}

Background: Kratom or Mitragyna speciosa Korth has been widely used to relieve the severity of opioid withdrawal in natural settings. However, several studies have reported that kratom may by itself cause dependence following chronic consumption. Yet, there is currently no formal treatment for kratom dependence. Mitragynine, is the major psychoactive alkaloid in kratom. Chronic mitragynine treatment can cause addiction-like symptoms in rodent models including withdrawal behaviour. In this study we assessed whether the prescription drugs, methadone, buprenorphine and clonidine, could mitigate mitragynine withdrawal effects. In order to assess treatment safety, we also evaluated hematological, biochemical and histopathological treatment effects.

Methods: We induced mitragynine withdrawal behaviour in a chronic treatment paradigm in rats. Methadone $(1.0 \mathrm{mg} / \mathrm{kg})$, buprenorphine $(0.8 \mathrm{mg} / \mathrm{kg})$ and clonidine $(0.1 \mathrm{mg} / \mathrm{kg})$ were i.p. administered over four days during mitragynine withdrawal. These treatments were stopped and withdrawal sign assessment continued. Thereafter, toxicological profiles of the treatments were evaluated in the blood and in organs.

Results: Chronic mitragynine treatment caused significant withdrawal behaviour lasting at least 5 days. Methadone, buprenorphine, as well as clonidine treatments significantly attenuated these withdrawal signs. No major effects on blood or organ toxicity were observed.

Conclusion: These data suggest that the already available prescription medications methadone, buprenorphine, and clonidine are capable to alleviate mitragynine withdrawal signs rats. This may suggest them as treatment options also for problematic mitragynine/ kratom use in humans.

Keywords: mitragynine, kratom, withdrawal, replacement, methadone, burprenorphine, clonidine 


\section{INTRODUCTION}

Mitragyna speciosa Korth or kratom is traditionally used in South-East Asia, particularly in Thailand and Malaysia, for its psychoactive effects. Kratom leaves have been claimed to have both psychostimulant- and opium-like narcotic effects. At low dose it acts as a stimulant, while being sedative at high doses (Jansen and Prast, 1988). Locals historically use kratom to combat exhaustion and survive working under bright sunlight through its psychostimulant-like effect.

Furthermore, kratom is also used to self-medicate for opioid withdrawal symptoms and as a replacement for heroin and morphine (Beckett et al., 1965; Grundmann, 2017). Currently, kratom emerged in the self-management of pain and opioid withdrawal, especially in the United States (Prozialeck, 2016; Grundmann, 2017). Kratom can be easily purchased on the internet. It has cheap prices and being marketed in many forms, from tablet to extract, in leaf form, as topical creams, balms or tinctures (Stanciu et al., 2019). In the United States, kratom is marketed and regulated as a dietary or herbal supplement. Individuals apply it for management of anxiety, pain, opioid use disorder, and depression (Boyer et al., 2008; Grundmann, 2017; Coe et al., 2019). Nevertheless, complications have arisen from this. The poorly regulated botanical and dietary supplement market which is also made up of adulterated products and where kratom products are sold, may partially account for the fatal cases (Obeng et al., 2020) that arise from their consumption. Indeed, death from kratom ingestion is exceedingly uncommon (Eastlack et al., 2020). Nonetheless, it can occur as a result of polysubstance abuse, which can contribute to an increased mortality risk (Neerman et al., 2013). Additionally, the Center for Disease Control and Prevention (CDC) reported 152 kratom-related deaths between the period of July 2016 and December 2017, all of which contained polydrug (Kuehn, 2019). Furthermore, 156 deaths have been linked to kratom use, with $87 \%$ being linked to polydrug use (Corkery et al., 2019).

Whilst kratom has benefits, it also has been reported that they can cause dependence and addiction-like symptoms after longterm consumption in humans (Vicknasingam et al., 2010; Ahmad and Aziz, 2012; Singh et al., 2014; Singh et al., 2018a; Müller et al., 2020; Anand and Hosanagar, 2021). Kratom withdrawal symptoms include, jerky movement, muscle ache, aggression, wet nose, and hostility in natural settings (Suwanlert, 1975). Furthermore, kratom users have been reported to have difficulties in combating kratom withdrawal while trying to stop its consumption (Ahmad and Aziz, 2012; Singh et al., 2014).

Kratom leaves contain over 40 alkaloids where mitragynine is the main indole alkaloid (Adkins et al., 2011; Yearsley, 2016). For this reason, we believed that mitragynine might be one of the alkaloids that modulate the effects in kratom. Currently, there is no specific treatment implemented in managing kratom dependence and withdrawal symptoms. Since no standardized treatment for kratom dependence is currently applied, therefore, the present study aims to investigate whether the available prescription drugs for opioid management; methadone, buprenorphine and clonidine, would mitigate the withdrawal symptoms caused by chronic mitragynine exposure.

\section{MATERIALS AND METHODS}

\section{Animals}

All animal experiments were performed in accordance with approved guidelines and regulations of the Universiti Sains Malaysia (USM) Institutional Animal Care and Use Committee (USM IACUC) [Reference number: USM/Animal Ethics Approval/2016/ (Santiago and Edelman, 1985) (736)]. Animals were purchased from Animal Research and Service Centre (ARASC), Universiti Sains Malaysia, Penang, Malaysia. All 30 tested animals were male Sprague-Dawley rats (200-300 g). They were naive and used in a single experiment only. Animals were socially housed in groups of six per cage under standard laboratory conditions, with temperaturecontrolled environment $\left(24 \pm 1^{\circ} \mathrm{C}\right)$ during habituation and were then placed individually prior to the treatment. The room was maintained on a $12 \mathrm{~h}$ light $/ 12 \mathrm{~h}$ dark normal cycle (lights on from 07:00 to 19:00 h). Animals were handled for one week prior to commencement of the experiments. Food and water were available ad libitum.

\section{Drugs Preparation}

Methadone hydrochloride, buprenorphine hydrochloride and clonidine hydrochloride were purchased from Sigma Chemicals Co. (United States). Mitragynine was extracted, isolated and verified from fresh leaves of Mitragyna speciosa at the Centre for Drug Research, Universiti Sains Malaysia as described previously (Utar et al., 2011). Purified mitragynine was confirmed by high performance liquid chromatography (HPLC) and proton nuclear magnetic resonance ( $\left.{ }^{1} \mathrm{H}-\mathrm{NMR}\right)$ (400 MHz) analysis (Jamil et al., 2013). Mitragynine obtained by this procedure was approximately $98 \%$ pure (Hassan et al., 2019). Fresh stocks of methadone, buprenorphine, mitragynine and clonidine were prepared daily according to the weight of animals in the experimental design. They were dissolved in vehicle $(20 \% \quad(\mathrm{v} / \mathrm{v})$ Tween 80 which was diluted with physiological saline $(0.9 \% \quad \mathrm{NaCl})$; Sigma Aldrich, United Kingdom) and injected intraperitoneally (i.p.).

\section{Experimental Design for Replacement Treatment in Mitragynine Withdrawal Model}

The previously established mitragynine withdrawal model was used (Hassan et al., 2021). Mitragynine (30 mg/kg, i.p.) was injected once per day over a period of 14 days. The vehicle group received $20 \%$ Tween 80 also once daily for 14 days. For both the vehicle- and mitragynine groups, withdrawal symptoms were assessed on day 15, twenty-four hours after abstinence from the drug. In this model, the effectiveness of the available prescription medications, methadone, buprenorphine and clonidine, were accessed. All the replacement treatments were applied for four days and then abruptly stopped on day 5 in order to determine whether or not the mitragynine withdrawal signs will resurface. This design followed the replacement routine described by Hassan et al. (2020). In a subsequent test, we examined hematological, biochemical and histopathological effects of the mitragynine and the replacement treatments. 
TABLE 1 | The counted signs and checked signs with the respective weighing factors for the evaluation of mitragynine-withdrawal severity in rats.

\begin{tabular}{|c|c|c|c|}
\hline Counted signs & Weighing factors & $\begin{array}{c}\text { Checked signs (Checked } \\
\text { every } 10 \mathrm{~min} \text { ) }\end{array}$ & Weighing factors \\
\hline Chewing & 2 & Squeaking on touch & 1 \\
\hline Head shakes & 2 & Hostility on handling & 1 \\
\hline Exploring & 1 & Diarrhoea & 1 \\
\hline Digging & 2 & - & - \\
\hline Yawning & 2 & - & - \\
\hline Teeth chattering & 2 & - & - \\
\hline Wet dog shakes & 2 & - & - \\
\hline Writhing & 2 & - & - \\
\hline
\end{tabular}

\section{Experiment I: Methadone, Buprenorphine and Clonidine Replacement Treatments in Mitragynine Withdrawn Rats.}

The methadone dose used in the present study $(1.0 \mathrm{mg} / \mathrm{kg}$, i. p.) was selected to be in the pharmacological range and below the $\mathrm{LD}_{50}$ value to reduce fatality risk (McCormick et al., 1984; Chevillard et al., 2010). Methadone was dissolved in vehicle (20\% Tween 80; Sigma Aldrich, United Kingdom) and injected i. p. $10 \mathrm{~min}$ before withdrawal testing, i.e., $23 \mathrm{~h} 50 \mathrm{~min}$ after the last mitragynine dose (Chevillard et al., 2010). Thereafter, methadone was repeatedly administered every $8 \mathrm{~h}$ (Chevillard et al., 2010) for four days of replacement treatment.

The buprenorphine dose used in the present study $(0.8 \mathrm{mg} / \mathrm{kg}$, i.p.) was selected to be in the pharmacological range of previous studies (Cowan et al., 1977; McLaughlin and Dewey, 1994; Morgan et al., 1999). Buprenorphine was dissolved in vehicle (20\% Tween 80; Sigma Aldrich, United Kingdom) and injected i.p. $30 \mathrm{~min}$ before withdrawal testing, i.e., $23.5 \mathrm{~h}$ after the last mitragynine dose (Cowan et al., 1977). Buprenorphine was then administered every $12 \mathrm{~h}$ (Schaap et al., 2012) for four days.

The clonidine dose used in the present study $(0.1 \mathrm{mg} / \mathrm{kg}$, i.p. $)$ was based on the previous study by Tierney et al. (1988). In the present study, clonidine was dissolved in vehicle (20\% Tween 80 ; Sigma Aldrich, United Kingdom) and injected i.p. 10 min before withdrawal testing, i.e., $23 \mathrm{~h} 50 \mathrm{~min}$ after the last mitragynine dose (Tierney et al., 1988; Sireesha et al., 2015). Thereafter, clonidine was administered every $12 \mathrm{~h}$ for four days (Feily and Abbasi, 2009; Moayeri et al., 2018).

\section{Assessment of Withdrawal Behaviour}

Trained observers who were blind to treatment and time points, scored all behaviours from video and counted the frequency of the signs of spontaneous withdrawal: chewing, head shakes, exploring, digging, yawning, teeth chattering, wet dog shakes, and writhing as well as checked the signs of squeaking on touch, hostility on handling, and diarrhoea. The observers showed an inter-rater reliability for this scoring of $r=0.99$. The recording was started once the animals were placed in an open field test box for $30 \mathrm{~min}$ and the withdrawal behaviour were scored. The test was performed daily for 4 days of replacement therapy and on day 5 when the treatment had stopped. The withdrawal behaviours were distinguished as "counted signs", including chewing, head shakes, exploring, digging, yawning, teeth chattering, wet dog shakes, writhing, and as "checked signs", including squeaking on touch, hostility on handling and diarrhoea. Thereby, counted signs and checked signs were further processed by multiplying with the respective weighting factors for evaluation of the severity of withdrawal signs using the previously described scoring method by Hassan et al. (2020), Rahman et al. (2002), and Sabetghadam et al. (2013) (Table 1).

\section{Experiment II}

\section{Hematological Analysis}

After behavioural studies ended on day 5, all the treated rats were euthanized with sodium pentobarbital (100 mg/kg) intraperitoneally. Blood samples were collected via cardiac puncture and transferred into tubes containing ethylenediamine tetraacetic acid (EDTA). Blood samples were analysed for several hematological parameters such as red blood cell count (Total RBC), haemoglobin, percentage of packed cell volume (PCV\%), mean corpuscular volume (MCV), mean corpuscular haemoglobin (MCH), mean corpuscular haemoglobin concentration (MCHC), percentage of red cell distribution width (RDW\%), total of white blood cell count (WBC), percentage of lymphocyte, monocytes, eosinophils, basophils, and platelet counts (PLT).

\section{Biochemical Analysis}

The collected blood was transferred into serum-separating tubes for biochemical analysis. The biochemical parameters analysed were total bilirubin, aspartate amino transferase (AST), alanine aminotransferase (ALT), alkaline phosphatase, sodium, potassium, chloride, urea, creatinine, total cholesterol, triglycerides, calcium, phosphorus, total protein, albumin, globulin and albumin/globulin ratio (A/G ratio).

\section{Histopathological Analysis}

On day 5, animal tissue samples of targeted organs (heart, lung, kidney, liver) were harvested after behavioural testing. The tissues were stained using Hematoxylin and Eosin. Then, the slides were viewed under light microscope equipped with a digital camera. The sections were analysed for structural changes, degenerative alterations, necrosis and signs of inflammation.

\section{Statistical Analysis}

All data were expressed as mean \pm standard error of the mean (SEM). The substitution treatments were analysed by two-way 
GLOBAL WITHDRAWAL SCORE VS DAYS

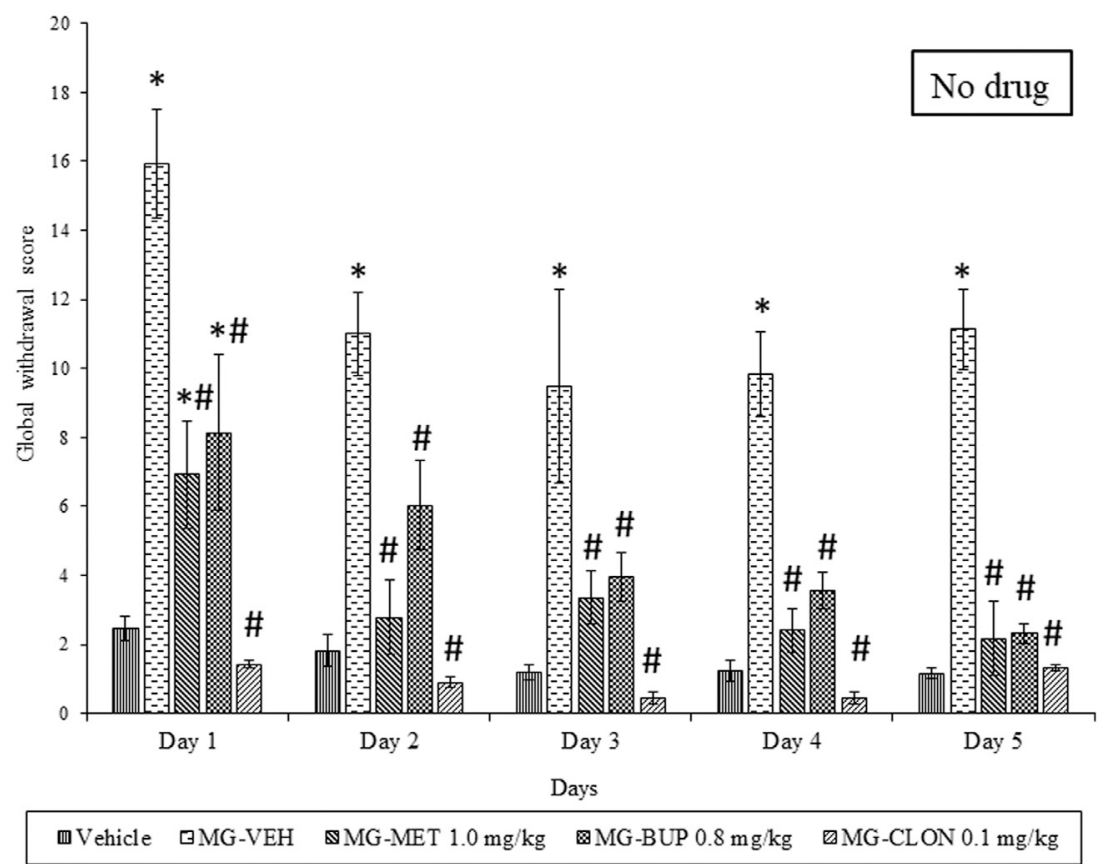

FIGURE 1 | Methadone (MET), Buprenorphine (BUP) and Clonidine (CLON) reduced behavioural signs of mitragynine withdrawal in rats. Data represent means ( \pm SEM) of global withdrawal signs ( $n=6 /$ group; ${ }^{*} p<0.05$, vs. Vehicle, $\# p<0.05$ vs. mitragynine-vehicle, MG-VEH).

ANOVA for repeated measures with test "day" as within factor and treatment combination as a "treatment" between factors. In order to analyse single group differences on each treatment day, pre-planned comparisons were calculated using Bonferroni test (Ramsey and Edwards, 1993). Hematological and biochemical parameters were analysed by one-way repeated measures ANOVA and Bonferroni post-hoc tests. Each of the hematological and biochemical parameters as fixed factor or within factor, whereas treatment combination is between factors. A significance level of $p<0.05$ was used to test for statistical significance. GraphPad Prism 8.0 software (GraphPad Software Inc., La Jolla, CA, United States) was used to perform the statistics.

\section{RESULT}

\section{Experiment I: Methadone, Buprenorphine and Clonidine Replacement Treatments in Attenuating Withdrawal Effects Due to Mitragynine}

We found that chronic mitragynine treatment induced significant withdrawal behaviour on all 5 days after cessation of administration (Figure 1). Methadone, buprenorphine, as well as clonidine significantly attenuated the mitragynine withdrawal effects on all 4 days of the replacement treatment, and on day 5 when no treatment was given. A two-way ANOVA showed significant treatment $\left(\mathrm{F}_{4,75}=77.69, p<0.0001\right)$ and day effects $\left(\mathrm{F}_{4,75}=9.327, p<0.0001\right)$, but no significant treatment $\times$ day interaction $\left(\mathrm{F}_{16,75}=1.222, p=0.2721\right)$. On day 1 , methadone significantly reduced withdrawal signs as compared to vehicle and mitragynine groups $(p<0.05)$ (Figure 1). From day 2 to day 4 as well as on day 5 on which no replacement treatment was given, there was a significant difference compared to the mitragynine group $(p<0.05)$, but not to the vehicle group $(p>0.05)$. Buprenorphine also significantly alleviated the withdrawal signs as compared to vehicle and mitragynine groups on day $1(p<0.05)$ (Figure 1). A significant mitigation of withdrawal signs was also observed from day 2 to day 5 , as compared to the mitragynine group $(p<0.05)$, but not compared to the vehicle group $(p>0.05)$. The strongest suppression of mitragynine withdrawal effects was observed after clonidine treatment (day $1-5$; vs. mitragynine-vehicle: $p<0.05)$. From day 1 to day 5, no significant difference was shown between the mitragynine-clonidine treated group compared to the vehicle group $(p>0.05)$ and significant result has been revealed as compared to mitragynine group $(p<0.05)$.

\section{Experiment II}

\section{Hematological and Biochemical Analysis}

Hematological and biochemical analyses of the blood samples were taken on day 5 and results are displayed in Tables 2, 3, respectively. The references range value of both hematological and biochemical analyses were based on these following studies Nugraheni et al. (2017), He et al. (2017), Houtmeyers et al. (2016) and Petterino and Argentino-Storino (2006). The hematological analysis revealed a significant increase in mean corpuscular 
TABLE 2 | Hematological analysis on day 5 in mitragynine replacement treatments.

\begin{tabular}{|c|c|c|c|c|c|c|}
\hline $\begin{array}{l}\text { Replacement } \\
\text { groups }\end{array}$ & Vehicle & $\begin{array}{c}\text { Mitragynine } \\
- \\
\text { Vehicle }\end{array}$ & $\begin{array}{l}\text { Mitragynine } 1 \mathrm{mg} / \mathrm{kg} \\
\text { Methadone }\end{array}$ & $\begin{array}{c}\text { Mitragynine } 0.8 \mathrm{mg} / \mathrm{kg} \\
\text { Buprenorphine }\end{array}$ & $\begin{array}{c}\text { Mitragynine } 1.1 \mathrm{mg} / \mathrm{kg} \\
\text { Clonidine }\end{array}$ & $\begin{array}{c}\text { References } \\
\text { range } \\
\text { value }\end{array}$ \\
\hline $\begin{array}{l}\text { Total RBC } \\
\left(\times 10^{\wedge} 12 / \mathrm{L}\right)\end{array}$ & $6.97 \pm 0.24$ & $8.23 \pm 0.6$ & $7.93 \pm 0.35$ & $8 \pm 0.17$ & $7.93 \pm 0.37$ & $6.39-8.01$ \\
\hline Hemoglobin (gm/L) & $155.67 \pm 8.19$ & $168 \pm 12.7$ & $168 \pm 4.36$ & $159 \pm 8.02$ & $156.67 \pm 9.61$ & $135-159$ \\
\hline PCV (\%) & $49.33 \pm 1.86$ & $47 \pm 0.04$ & $45 \pm 1.73$ & $46.33 \pm 1.76$ & $43.67 \pm 0.02$ & $42-49$ \\
\hline MCV (fL) & $58.33 \pm 2.03$ & $57 \pm 1.73$ & $58 \pm 0.58$ & $59 \pm 2.08$ & $55 \pm 1.15$ & $58.01-67.00$ \\
\hline $\mathrm{MCH}(\mathrm{pg})$ & $20.67 \pm 0.33$ & $20.33 \pm 0.33$ & $21 \pm 0.58$ & $19 \pm 1.53$ & $19.67 \pm 0.33$ & $18.70-21.20$ \\
\hline $\mathrm{MCHC}(\mathrm{g} / \mathrm{L})$ & $316.67 \pm 8.82$ & $360 \pm 5.77$ & $376.67 \pm 8.82^{\star}$ & $320 \pm 20$ & $360 \pm 5.77$ & 310-336 \\
\hline RDW (\%) & $15.17 \pm 0.42$ & $14.93 \pm 0.94$ & $14.93 \pm 0.12$ & $15.4 \pm 0.58$ & $14.93 \pm 0.26$ & $13.03-16.57$ \\
\hline Total WBC (x 109/L) & $4.2 \pm 1.18$ & $4.8 \pm 1.29$ & $4.4 \pm 0.71$ & $6.47 \pm 0.18$ & $5.13 \pm 0.96$ & $3.00-9.22$ \\
\hline Lymphocytes (\%) & $76.33 \pm 2.03$ & $66 \pm 5.86$ & $65.67 \pm 6.64$ & $76.33 \pm 1.45$ & $69 \pm 1.53$ & $51.8-89.7$ \\
\hline Monocytes (\%) & $2.67 \pm 0.67$ & $0.33 \pm 0.33$ & $3 \pm 0.58$ & $2.67 \pm 0.67$ & $0.67 \pm 0.33$ & $1.3-6.0$ \\
\hline Eosinophils (\%) & $0 \pm 0$ & $0.33 \pm 0.33$ & $0.33 \pm 0.33$ & $0.58 \pm 0.01$ & $0 \pm 0$ & $0.5-7.2$ \\
\hline Basophils (\%) & $0 \pm 0$ & $0 \pm 0$ & $0 \pm 0$ & $0 \pm 0$ & $0 \pm 0$ & $0-0.6$ \\
\hline $\begin{array}{l}\text { Platelet count } \\
\left(\times 10^{\wedge} 9 / \mathrm{L}\right)\end{array}$ & $682 \pm 112.65$ & $529 \pm 62.69$ & $702.33 \pm 18.89$ & $946.33 \pm 3.53 \#$ & $483.33 \pm 39.54$ & $529.0-1,383.0$ \\
\hline
\end{tabular}

Total RBC, red blood cell count; PCV\%, percentage of packed cell volume; MCV, mean corpuscular volume; MCH, mean corpuscular haemoglobin; MCHC, mean corpuscular haemoglobin concentration; RDW\%, percentage of red cell distribution width; WBC, total of white blood cell count, Lymphocytes (\%), Percentage of lymphocyte; Monocytes (\%), Percentage of monocytes; Eosinophils (\%), Percentage of eosinophils; Basophils (\%), Percentage of basophils; PLT, Platelet counts.

Data represent means $\pm S E M$ of $n=6$ rats/group * $\mathrm{p}<0.05$ vs. Vehicle, $\# p<0.05$ vs. Mitragynine-Vehicle, analysed by one-way repeated measures ANOVA and Bonferroni post-hoc test.

\begin{tabular}{|c|c|c|c|c|c|c|}
\hline Replacement groups & Vehicle & $\begin{array}{l}\text { Mitragynine - } \\
\text { Vehicle }\end{array}$ & $\begin{array}{l}\text { Mitragynine } 1 \mathrm{mg} / \mathrm{kg} \\
\text { Methadone }\end{array}$ & $\begin{array}{l}\text { Mitragynine } 0.8 \mathrm{mg} / \mathrm{kg} \\
\text { Buprenorphine }\end{array}$ & $\begin{array}{c}\text { Mitragynine } \\
0.1 \mathrm{mg} / \mathrm{kg} \text { Clonidine }\end{array}$ & $\begin{array}{c}\text { References } \\
\text { range } \\
\text { value }\end{array}$ \\
\hline Total bilirubin (umol/L) & $1.71 \pm 0$ & $2.28 \pm 0.57$ & $1.71 \pm 0$ & $2.28 \pm 0.57$ & $2.28 \pm 0.57$ & $0.0-5.1$ \\
\hline $\begin{array}{l}\text { Aspartate } \\
\text { aminotransferase, AST } \\
(\mathrm{U} / \mathrm{L})\end{array}$ & $117 \pm 4.58$ & $205.33 \pm 36.08$ & $169 \pm 20.03$ & $147 \pm 1$ & $220.33 \pm 35.57$ & $56.1-201.8$ \\
\hline $\begin{array}{l}\text { Alanine aminotransferase, } \\
\text { ALT (U/L) }\end{array}$ & $59 \pm 6.11$ & $74 \pm 2.08$ & $53 \pm 2.31$ & $58.33 \pm 3.38$ & $55.33 \pm 6.69$ & $34.9-218.1$ \\
\hline Alkaline phosphatase (U/L) & $299.67 \pm 28.01$ & $381.67 \pm 119.7$ & $337.33 \pm 48.55$ & $421 \pm 86.97$ & $253.33 \pm 32.69$ & $131.6-459.0$ \\
\hline Sodium (mmol/L) & $141.67 \pm 1.45$ & $139.33 \pm 0.67$ & $141 \pm 1.73$ & $143.67 \pm 0.67$ & $140.33 \pm 0.88$ & 121.9-162.6 \\
\hline Potassium (mmol/L) & $6.7 \pm 1.26$ & $7.67 \pm 0.12$ & $7.8 \pm 0.85$ & $6.77 \pm 0.24$ & $7.1 \pm 0.15$ & $4.0-8.0$ \\
\hline Chloride (mmol/L) & $102.33 \pm 0.88$ & $102.33 \pm 0.33$ & $103 \pm 0.58$ & $104 \pm 0$ & $104.67 \pm 1.2$ & $81.5-104.0$ \\
\hline Urea (mmol/L) & $9.80 \pm 0.3$ & $8.33 \pm 0.45$ & $8.05 \pm 0.11$ & $14.45 \pm 6.04$ & $10.03 \pm 0.45$ & $4.32-34.4$ \\
\hline Creatinine (umol/L) & $49.87 \pm 2.35$ & $46.93 \pm 0.59$ & $46.35 \pm 1.63$ & $73.92 \pm 33.93$ & $43.71 \pm 1.28$ & $35.4-79.6$ \\
\hline Total cholesterol (mmol/L) & $1.70 \pm 0.08$ & $2.1 \pm 0.11$ & $1.59 \pm 0.09 \#$ & $1.47 \pm 0.07 \#$ & $1.74 \pm 0.11$ & $0.68-1.77$ \\
\hline Triglycerides (mmol/L) & $0.93 \pm 0.19$ & $0.82 \pm 0.19$ & $0.98 \pm 0.09$ & $0.99 \pm 0.14$ & $0.65 \pm 0.15$ & $0.23-0.99$ \\
\hline Calcium (mmol/L) & $2.41 \pm 0.11$ & $2.33 \pm 0.11$ & $2.48 \pm 0.01$ & $2.38 \pm 0.03$ & $2.28 \pm 0.06$ & $2.1-2.9$ \\
\hline Phosphorus (mmol/L) & $2 \pm 0.30$ & $2.36 \pm 0.28$ & $2.13 \pm 0.25$ & $2.22 \pm 0.09$ & $2.35 \pm 0.17$ & $1-3.94$ \\
\hline Total protein (g/L) & $70 \pm 4.36$ & $73.67 \pm 1.76$ & $65.67 \pm 0.88$ & $67.67 \pm 1.86$ & $69.67 \pm 3.38$ & $52-71$ \\
\hline Albumin (g/L) & $27 \pm 2.08$ & $28 \pm 0.58$ & $25.67 \pm 0.88$ & $26 \pm 1.53$ & $26.33 \pm 1.33$ & $26.85-34.55$ \\
\hline Globulin (g/L) & $43.33 \pm 2.33$ & $45.67 \pm 2.19$ & $40 \pm 1.53$ & $41.67 \pm 1.2$ & $43.33 \pm 3.18$ & $13-48$ \\
\hline Albumin/Globulin ratio (g/L) & $0.6 \pm 0.06$ & $0.63 \pm 0.07$ & $0.63 \pm 0.03$ & $0.63 \pm 0.03$ & $0.63 \pm 0.07$ & $0.6-1.21$ \\
\hline
\end{tabular}

Data represent means \pm SEM of $n=6$ rats/group ${ }^{*} \mathrm{p}<0.05$ vs. Vehicle, $\# \mathrm{p}<0.05$ vs. Mitragynine-Vehicle, analysed by one-way repeated measures ANOVA and Bonferroni post-hoc test.

hemoglobin concentration (MCHC). This was higher than the reference range in the mitragynine-methadone group and significantly increased compared to the vehicle control group $(p<0.05)$. A significant increase in platelet count was found in the mitragynine-buprenorphine group ( $p<0.05$ vs vehicle; Table 2). The biochemical analysis revealed a significant reduction of total cholesterol in the mitragynine-methadone and mitragyninebuprenorphine groups $(p<0.05)$ compared to vehicle control (Table 3).

\section{Histopathology Analysis}

The results of histopathological examination of the transverse sections of heart, lung, kidney, and liver are shown in Table 4. In general, there were no differences between the vehicle and the treatment groups by cross-examination of the microscopic structures of the heart, kidney and liver. However, the lung structure revealed a slight difference effect in the alveoli size in all replacement treated groups when compared to the vehicle group (Table 4). 
TABLE 4 | The microscopic structures of the organs in mitragynine replacement treatments.

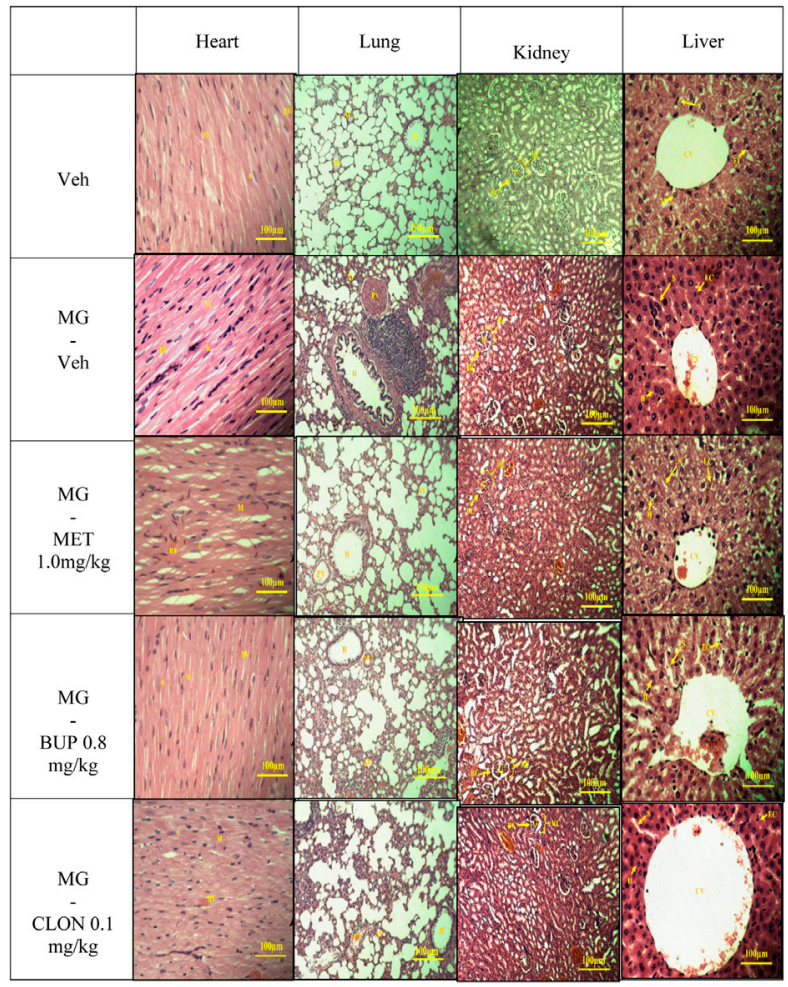

\section{DISCUSSION}

When a person is compelled to take a drug on a regular or continuous basis in order to achieve psychic effects on mental state, such as euphoria, and to avoid physical discomfort (withdrawal), this is referred to as drug dependence (Gupta and Gupta, 2018; Müller, 2020). Dependence in kratom is well documented in human (Suwanlert, 1975; Vicknasingam et al., 2010; Ahmad and Aziz, 2012; Singh et al., 2014). Nevertheless, although kratom has been reported to cause dependence and withdrawal signs, these symptoms are usually milder than after opiate withdrawal (Prozialeck, 2016; Saingam et al., 2016; Grundmann, 2017; Singh et al., 2018b; Swogger and Walsh, 2018). Singh et al. (2018b) reported that kratom depended patients did not seek for medication as kratom withdrawal symptoms were mostly rather mild and only lasted between one to three days. A widely held view is that kratom is not as risky as opioid drugs and that the danger can be outweighed by the potential benefits (Prozialeck, 2016). However, aggressive kratom consumption pattern may cause escalation of consumption and more severe withdrawal signs (Müller et al., 2021). Indeed, withdrawal periods are highly aversive, which makes it hard for an individual to maintain abstinence (Swogger and Walsh, 2018).

At the moment, there is no particular treatment for kratom dependence and withdrawal symptoms. Nonetheless, several studies have been conducted in which buprenorphine was substituted for kratom (Buresh, 2018; Bowe and Kerr, 2020;
Lei et al., 2021). The recent study by Weiss and Douglas (Weiss and Douglas, 2021) demonstrated that patients who used less than $20 \mathrm{~g}$ of kratom per day could begin opioid agonist therapy with 4/ $1 \mathrm{mg}-8 / 2 \mathrm{mg}$ buprenorphine-naloxone/day, whereas patients who used more than $40 \mathrm{~g}$ of kratom per day could begin with $12 / 3 \mathrm{mg}$ $16 / 4 \mathrm{mg}$ buprenorphine-naloxone/day. Kratom leaves do contain more than 40 alkaloids, with mitragynine being the most common indole alkaloid (Adkins et al., 2011; Yearsley, 2016). As a result, we presumed that mitragynine was one of the alkaloids that modulated the effects of kratom. However, one feature that should be noted is that the alkaloid contents vary according to geographical regions and seasons (Hassan et al., 2013). Stages in leaf maturity too are a contributing factor (Raffa, 2015). Studies have shown that mitragynine content is much more abundant in Thai kratom as compared to the Malaysian species, amounting to 66.2 and $12 \%$, respectively (Takayama et al., 1998; Takayama, 2004). This would suggest that kratom substitution treatment is difficult to be evaluated due to differences in mitragynine content. Therefore, the current study will focus on mitragynine rather than kratom dependence. Mitragynine is a psychoactive substance which also can produce dependence for which no pharmacotreatment is available yet. Mitragynine has been reported to cause physical dependence after spontaneously mitragynine withdrawal (Hassan et al., 2021) and after naloxone-precipitated withdrawal (Harun et al., 2020) in animal studies. In addition, Yusoff et al. (2016) also reported that chronic mitragynine withdrawal triggers anxiety-like behaviour in rats. Because there is presently no established treatment for kratom dependence, the present study investigated the effectiveness of methadone, buprenorphine, and clonidine, in attenuating the withdrawal symptoms induced by persistent mitragynine exposure. Buprenorphine, methadone, and clonidine have been identified as the most effective opioid detoxification medications (Meader, 2010). Thus, that is why we used those treatments in the current study. In addition, the opioid and non-opioid mitragynine receptors that may be involved in mitragynine withdrawal were also being considered, and the drug used in the current study was influenced by them. This research is, to the best of our knowledge, the first study on the effects of methadone, buprenorphine and clonidine on mitragynine withdrawal symptoms.

We recently published a rat mitragynine withdrawal model (Hassan et al., 2021). Thus therefore, we used this model in the following experiments in this present work. Overall, this study showed a marked reduction in withdrawal symptoms in mitragynine withdrawn rats receiving methadone, buprenorphine and clonidine. In addition, no resurface of the withdrawal symptoms was seen on day 5 of the cessation (Figure 1). This suggests that methadone, buprenorphine and clonidine are capable in alleviating mitragynine withdrawal signs during and after the replacement therapy. This may also imply that mitragynine withdrawal modulates the same receptors as the mechanisms of action in methadone, buprenorphine and clonidine.

Mitragynine has been proved to bind at opioid receptor, which has been demonstrated by several researchers via in vivo and in vitro studies. Matsumoto et al. (Matsumoto et al. (1996a) has reported that involvement of opioid receptors in the action of mitragynine. Mitragynine acting on opioid systems can also be 
observed in the studies of ileum motility inhibition (Watanabe et al., 1997) and inhibition of gastric acid secretion (Tsuchiya et al., 2002) that has been reversed by naloxone. Furthermore, Shamima et al. (2012) also reported the antinociceptive effects of mitragynine when it showed a significant decrease in the latency time compared to mitragynine alone after intraperitoneally administered of naloxone (non-selective opioid antagonist) and naltrindole (delta-opioid antagonist). Naloxonazine, a $\mu 1$ receptor antagonist did reduce the antinociceptive effect of mitragynine, but it is not statistically significant, which indicates that mitragynine may not only act specifically on $\mu 1$ receptor. However, norbinaltorpimine (norBNI) (i.p.) partially blocked the effect of mitragynine and significantly decreased the latency time when compared with mitragynine alone from 30 to $60 \mathrm{~min}$, but not up to $120 \mathrm{~min}$ time, indicate that mitragynine may partially act via kappa opioid receptor (Shamima et al., 2012). In addition, Kruegel et al. (2016) has demonstrated that mitragynine acts as a partial agonist at the human mu-opioid receptor (MOP) and competitive antagonists at kappa-(KOP) and delta- (DOP) opioid receptors in in intro study. Indeed, this matter is still in question with the facts about whether mitragynine fully or partially works on the mu-opioid receptor remaining uncertain. Nonetheless, Yusoff et al. (2017) revealed that mitragynine-induced CPP establishment, but not expression, is mediated by an opioid receptor mechanism. Moreover, recently, the effect of naloxone on precipitated of mitragynine withdrawal effects was described by Harun et al. (2020), suggesting that the mu-opioid receptor is responsible for the development of mitragynine dependence.

However, Hiranita et al. (2019) suggested that mitragynine is not mediated through opioid receptor, as naltrexone did not antagonize the effects of mitragynine. It was proposed that activation of serotonergic and noradrenergic pathways along the spinal contributed to the antinociceptive activity of mitragynine (Matsumoto et al., 1996b). It also reported to bind at non-opioid receptors includes alpha-2 adrenergic receptors, adenosine $A_{2} a$ receptors, dopamine $\mathrm{D}_{2}$ receptors, and the serotonin receptors 5- $-\mathrm{HT}_{2 \mathrm{C}}$ and 5- $\mathrm{HT}_{7}$ (Boyer et al., 2008; Prozialeck et al., 2012; Kruegel and Grundmann, 2018). Currently, an in vitro study evaluated the adrenergic effects by mitragynine using human monoclonal receptors expressed in Chinese hamster ovary $(\mathrm{CHO})$ cells and revealed that mitragynine is a partial agonist at alpha ${ }_{1 \mathrm{~A}}$ and ${ }_{\mathrm{D}}$ adrenergic receptors (Obeng et al., 2020).

Methadone and buprenorphine are both opioids, acting fully and partially on mu-opioid receptor, respectively (Kleber, 2007). Methadone and buprenorphine have been approved by the FDA in opioid replacement therapy (Bart, 2012). Methadone safety is well documented and proven (Kreek, 1973). However, if taken beyond the tolerance of the person, methadone could cause respiratory depression (Bart, 2012). The respiratory depression could also be fatal in the event of overdose since there is no ceiling level to it (Mattick et al., 2008). Moreover, unknown drug-drug interaction can also lead to death. Records indicate that methadone patients who use other controlled drugs in conjunction with methadone commonly face serious adverse effects (Mattick et al., 2008). Since the 1970s, buprenorphine has been accepted as an alternative treatment of opioid dependence (Mattick et al., 2008). Buprenorphine is also used as an analgesic in acute pain management. Buprenorphine has ceiling effects on respiratory depression (Ling and Compton, 2005). In contrast, a full agonist for respiratory depression which caused a robust decrease in respiratory ventilation following intracerebroventricular buprenorphine administration has been reported by Kuo et al. (2015). Moreover, buprenorphine also does not appear to exhibit a ceiling effect for analgesia (Dahan et al., 2006). At high dose, it antagonizes the analgesic effects of other opioids thereby complicating management of pain in patients maintained on high-dose buprenorphine (Heinzerling et al., 2019). Its antagonist properties can also cause a precipitation of acute opiate withdrawal effects if administered to an individual who is physically dependent on opioids.

Clonidine is a non-opioid drug, that is a partial agonist of alpha $_{2}$-adrenergic receptors (Giovannitti et al., 2015; Arora and Vohora, 2016). It was used in opioid substitution treatment over the years (Jamadarkhana and Gopal, 2010). It has analgesic effects (Kariya et al., 1998) and has been reported to decrease opioid dosage without affecting the quality of analgesia (Rostaing et al., 1991). It can reduce opiate withdrawal signs in inpatient and outpatient settings (Washton and Resnick, 1981; Tierney et al., 1988 ), via binding to $\alpha_{2}$-autoreceptors in the locus coeruleus and suppressing hyperactivity during withdrawal (Kleber, 2007). However, clonidine has adverse effects, particularly hypotension, which can restrict optimal clonidine dose for opioid withdrawal. It was reported to cause rebound hypertensive episodes in long-term clonidine therapy but proved as safe in short-term use (Kariya et al., 1998). Kleber (2007) also showed that clonidine can be used to treat residual mild withdrawal symptoms for a few days to a week as long as the patient does not become hypotensive. Nevertheless, clonidine has been reported to be less effective compared to methadone during early opioid detoxification phase when withdrawal symptoms were more pronounced and patients more likely to drop out (Mattick and Hall, 1996). On the other hand, clonidine showed in clinical trial a similar efficacy as buprenorphine in the reduction of withdrawal symptoms (Cheskin et al., 1994; Ziaaddini et al., 2012). Clonidine treated patients however suffered from lower blood pressure compared to buprenorphine treated patients (Cheskin et al., 1994).

\section{Hematological, Biochemical and Histopathological Changes in Mitragynine and the Replacement Drugs}

Biochemical and histopathological evaluations following mitragynine and/or the replacement drugs in blood and selected vital organs have also been conducted in the present study. In the hematological analysis (Table 2), MCHC increases in mitragyninevehicle, mitragynine- $0.1 \mathrm{mg} / \mathrm{kg}$ clonidine and mitragynine$1.0 \mathrm{mg} / \mathrm{kg}$ methadone. This might be due to the withdrawal effect that might be still exist in the body of the rats. Moreover, a substantial rise in $\mathrm{MCHC}$ level had also been reported in heroin and opium dependent and withdrawal groups (Haghpanah et al., 2010). In addition, the mitragynine- $0.1 \mathrm{mg} / \mathrm{kg}$ clonidine treatment lowered platelet count level below the normal reference range without affecting other hematological parameters. This indicates 
that the rats might be affected with biological variations namely variability between individual rats and temporal variation (Peng et al., 2004), which warrants further details investigations.

In biochemical analysis (Table 3), mitragynine- $1.0 \mathrm{mg} / \mathrm{kg}$ methadone and mitragynine- $0.8 \mathrm{mg} / \mathrm{kg}$ buprenorphine significantly reduced the total cholesterol level as compared to mitragynine-vehicle within the normal reference range value. A high level of total cholesterol has also been reported among kratom users who had a high daily mean frequency of kratom use (Leong Bin Abdullah et al., 2020).

Overall, a healthy set of organ cells except for lung can be observed in light microscopy examination of histopathology of all mitragynine replacement groups (Table 4). Previously, Macko et al. (1972) performed a subchronic study in rats and dogs in which no adverse effects were seen after oral administration of 5 or $50 \mathrm{mg} / \mathrm{kg} /$ day of mitragynine for six weeks, five days a week. Another subchronic study conducted by Sabetghadam et al. (2013) reported that mitragynine was relatively safe at lower subchronic doses $(1-10 \mathrm{mg} / \mathrm{kg}$, oral), but showed toxicity at the highest dose (subchronic 28 days: $100 \mathrm{mg} / \mathrm{kg}$, oral) in the liver, kidney and brain. This dose caused also hematological and biochemical changes. All these toxicity data were reported after oral application though, which differs from the present study, which used i.p. applications. After i.p. administration, the primary route of absorption is through the mesenteric vessels, which drain into the portal vein and pass through the liver (Lukas et al., 1971). Substances administered i.p. can, therefore, undergo hepatic metabolism before reaching the systemic circulation (Turner et al., 2011). Moreover, in all treated groups, particularly the mitragynine-vehicle group, mild lung histopathological changes were observed compared with vehicle control group (Table 4), suggesting that the selected doses of drugs administration at determined duration, were too small to cause histopathological damage but sufficient to show signs of drug intoxication.

Opiates, stimulants, and cannabinoids are three classes of drugs that can cause respiratory manifestation (Glassroth et al., 1987). There are pulmonary patho-histological findings that have the direct effect on lung; edema, pulmonary hemorrhage and appear of siderophages, pulmonary artery medial hypertrophy, panacinar emphysema, bronchiolitis obliterans, interstitial pneumonia or fibrosis (Karch and Stephens, 2000). In addition, Awadalla and Salah-Eldin (2016) reported that opioids can cause a drop in plasma antioxidant levels, possibly indicating that the antioxidant defence mechanism against oxidative damage has failed. Indeed, oxidative stress during mitragynine withdrawal has been reported by Hassan et al. (2021). Therefore, the mild lung histopathological changes might be related to oxidative stress.

Opioid usage is inextricably connected to respiratory depression, or hypoventilation. However, it has an indirect effect on the lungs (Radke et al., 2014). Respiratory depression occurs when the body is unable to efficiently eliminate carbon dioxide. This can result in the lungs' inefficient utilisation of oxygen. As a result, the body produces more carbon dioxide and has insufficient oxygen. Basically, muopioid receptors are mostly found in the brainstem and are expressed on neurons that govern breathing (Boom et al., 2012). The activation of mu-opioid receptors causes opioid-induced analgesia as well as respiratory depression (Boom et al., 2012). Opioids exert their respiratory depressant effect via two distinct mechanisms: decreased chemoreceptor sensitivity and decreased activity in the central respiratory centres (White and Irvine, 1999). The carotid and aortic bodies, as well as the lungs, contain peripheral chemoreceptors. They boost signal transduction in response to decreased partial pressure of oxygen $\left(\mathrm{pO}_{2}\right)$ or increased partial pressure of carbon dioxide $\left(\mathrm{pCO}_{2}\right)$. The central receptors, which are located in the medulla but separate from the main respiratory centre, respond only to elevated $\mathrm{pCO}_{2}$ (Radke et al., 2014). $\mathrm{Mu}$ - and delta opioid receptors are found in the central respiratory regions of the medulla (Radke et al., 2014). The respiratory centre's opioid activity induces a decrease in respiratory rate and tidal volume, both of which can contribute to a decrease in minute ventilation (White and Irvine, 1999). These effects are also dose-dependent where, at low dosages of opiates appear to decrease tidal volume, whereas larger doses appear to decrease both tidal volume and respiratory rate (Santiago and Edelman, 1985). In addition, in kratom itself, no single case can be solely attributed to respiratory failure, a sharp contrast to other opioids where respiratory depression is the most common cause of death (Kruegel and Grundmann, 2018). Plus, even though mitragynine activated the G-protein-mediated signaling pathway much like traditional opioids, it did not "recruit" $\beta$-arrestin-2 (Váradi et al., 2016), suggested that mitragynine has less side effect in terms of respiratory depression while it remains as a potent analgesic.

\section{CONCLUSION}

In conclusion, four-day replacement therapy with available prescription drugs, methadone, buprenorphine, and clonidine, significantly attenuated mitragynine withdrawal signs in rats. This is the first study that reports these possible treatments for mitragynine withdrawal. As the present mitragynine substitution treatment was a preliminary study, further investigations would be required to confirm these findings in future.

\section{DATA AVAILABILITY STATEMENT}

The raw data supporting the conclusions of this article will be made available by the authors, without undue reservation.

\section{ETHICS STATEMENT}

The animal study was reviewed and approved by Universiti Sains Malaysia (USM) Institutional Animal Care and Use Committee. Written informed consent was obtained from the owners for the participation of their animals in this study.

\section{AUTHOR CONTRIBUTIONS}

$\mathrm{ZH}$ conceptualized the idea. $\mathrm{ZH}$ and $\mathrm{RH}$ designed, performed the experiments and analysed data. $\mathrm{RH}, \mathrm{SS}, \mathrm{CM}$ and $\mathrm{ZH}$ wrote the paper. All authors read and approved the manuscript. 


\section{FUNDING}

This work was supported by the Higher Education Centre of Excellence (HiCoE) PHASE II special funding (304/CDADAH/ 4401009), FRGS (203.CDADAH.6711957) and Yang di-Pertuan Agong (BYDPA) scholarship.

\section{REFERENCES}

Adkins, J. E., Boyer, E. W., and McCurdy, C. R. (2011). Mitragyna Speciosa, a Psychoactive Tree from Southeast Asia with Opioid Activity. Curr. Top. Med. Chem. 11, 1165-1175. doi:10.2174/156802611795371305

Ahmad, K., and Aziz, Z. (2012). Mitragyna Speciosa Use in the Northern States of Malaysia: A Cross-Sectional Study. J. Ethnopharmacology 141, 446-450. doi:10.1016/j.jep.2012.03.009

Anand, A., and Hosanagar, A. (2021). The Addictive Potential and Challenges with Use of the "Herbal Supplement" Kratom: A Case Report and Literature Review. Pain Med.. pnab126. doi:10.1093/pm/pnab126

Arora, S., and Vohora, D. (2016). Comparative Evaluation of Partial a2Adrenoceptor Agonist and Pure a2-Adrenoceptor Antagonist on the Behavioural Symptoms of Withdrawal after Chronic Alcohol Administration in Mice. Basic Clin. Pharmacol. Toxicol. 119, 202-209. doi:10.1111/bcpt.12566

Awadalla, E. A., and Salah-Eldin, A.-E. (2016). Molecular and Histological Changes in Cerebral Cortex and Lung Tissues under the Effect of Tramadol Treatment. Biomed. Pharmacother. 82, 269-280. doi:10.1016/j.biopha.2016.04.024

Bart, G. (2012). Maintenance Medication for Opiate Addiction: The Foundation of Recovery. J. Addict. Dis. 31, 207-225. doi:10.1080/10550887.2012.694598

Beckett, A., Shellard, E., and Tackie, A. (1965). THE MITRAGYNA SPECIES of ASIA - Part IV. The Alkaloids of the Leaves ofMitragyna speciosaKorth.. Isolation of Mitragynine and Speciofolinel. Planta Med. 13, 241-246. doi:10.1055/s-0028-1100118

Boom, M., Niesters, M., Sarton, E., Aarts, L., W. Smith, T., and Dahan, A. (2012). Non-analgesic Effects of Opioids: Opioid-Induced Respiratory Depression. Cpd 18, 5994-6004. doi:10.2174/138161212803582469

Bowe, A., and Kerr, P. L. (2020). A Complex Case of Kratom Dependence, Depression, and Chronic Pain in Opioid Use Disorder: Effects of Buprenorphine in Clinical Management. J. Psychoactive Drugs 52, 447-452. doi:10.1080/02791072.2020.1773586

Boyer, E. W., Babu, K. M., Adkins, J. E., McCurdy, C. R., and Halpern, J. H. (2008). Self-treatment of Opioid Withdrawal Using Kratom (Mitragynia Speciosa Korth). Addiction 103, 1048-1050. doi:10.1111/j.1360-0443.2008.02209.x

Buresh, M. (2018). Treatment of Kratom Dependence with BuprenorphineNaloxone Maintenance. J. Addict. Med. 12, 481-483. doi:10.1097/ adm.0000000000000428

Cheskin, L. J., Fudala, P. J., and Johnson, R. E. (1994). A Controlled Comparison of Buprenorphine and Clonidine for Acute Detoxification from Opioids. Drug and Alcohol Dependence 36, 115-121. doi:10.1016/0376-8716(94) 90093-0

Chevillard, L., Mégarbane, B., Baud, F. J., Risède, P., Declèves, X., Mager, D., et al. (2010). Mechanisms of Respiratory Insufficiency Induced by Methadone Overdose in Rats. Addict. Biol. 15, 62-80. doi:10.1111/j.1369-1600.2009.00184.x

Coe, M. A., Pillitteri, J. L., Sembower, M. A., Gerlach, K. K., and Henningfield, J. E. (2019). Kratom as a Substitute for Opioids: Results from an Online Survey. Drug and Alcohol Dependence 202, 24-32. doi:10.1016/ j.drugalcdep.2019.05.005

Corkery, J. M., Streete, P., Claridge, H., Goodair, C., Papanti, D., Orsolini, L., et al. (2019). Characteristics of Deaths Associated with Kratom Use. J. Psychopharmacol. 33, 1102-1123. doi:10.1177/0269881119862530

Cowan, A., Lewis, J. W., and Macfarlane, I. R. (1977). Agonist and Antagonist Properties of Buprenorphine, a New Antinociceptive Agent. Br. J. Pharmacol. 60, 537-545. doi:10.1111/j.1476-5381.1977.tb07532.x

Dahan, A., Yassen, A., Romberg, R., Sarton, E., Teppema, L., Olofsen, E., et al. (2006). Buprenorphine Induces Ceiling in Respiratory Depression but Not in Analgesia. Br. J. Anaesth. 96, 627-632. doi:10.1093/bja/ael051

\section{ACKNOWLEDGMENTS}

We would like to thank Siti Najmi Syuhadaa Bakar, Noorul Hamizah Mat, Mohamad Azmeer Effendy Md Salim, Mohamad Anuar Ahad and Tiang Ning (Centre for Drug Research, Universiti Sains Malaysia) for their technical assistance.

Eastlack, S. C., Cornett, E. M., and Kaye, A. D. (2020). Kratom-Pharmacology, Clinical Implications, and Outlook: A Comprehensive Review. Pain Ther. 9, 55-69. doi:10.1007/s40122-020-00151-x

Feily, A., and Abbasi, N. (2009). The Inhibitory Effect of Hypericum perforatum Extract on Morphine Withdrawal Syndrome in Rat and Comparison with Clonidine. Phytother. Res. 23, 1549-1552. doi:10.1002/ptr.2807

Giovannitti, J. A., Jr., Thoms, S. M., and Crawford, J. J. (2015). Alpha-2 Adrenergic Receptor Agonists: A Review of Current Clinical Applications. Anesth. Prog. 62, 31-38. doi:10.2344/0003-3006-62.1.31

Glassroth, J., Adams, G. D., and Schnoll, S. (1987). The Impact of Substance Abuse on the Respiratory System. Chest 91, 596-602. doi:10.1378/chest.91.4.596

Grundmann, O. (2017). Patterns of Kratom Use and Health Impact in the USResults from an Online Survey. Drug and Alcohol Dependence 176, 63-70. doi:10.1016/j.drugalcdep.2017.03.007

Gupta, P. (2018). "Drugs of Use, Dependence, and Abuse," in Illustrated Toxicology. Editor PK Gupta (Academic Press), 331-356. doi:10.1016/b9780-12-813213-5.00012-2

Haghpanah, T., Afarinesh, M., and Divsalar, K. (2010). A Review on Hematological Factors in Opioid-dependent People (Opium and Heroin) after the Withdrawal Period. Addict. Health 2, 9-16.

Harun, N., Johari, I. S., Mansor, S. M., and Shoaib, M. (2020). Assessing Physiological Dependence and Withdrawal Potential of Mitragynine Using Schedule-Controlled Behaviour in Rats. Psychopharmacology 237, 855-867. doi:10.1007/s00213-019-05418-6

Hassan, R., Othman, N., Mansor, S. M., Müller, C. P., and Hassan, Z. (2021). Proteomic Analysis Reveals Brain Rab35 as a Potential Biomarker of Mitragynine Withdrawal in Rats. Brain Res. Bull. 172, 139-150. doi:10.1016/ j.brainresbull.2021.04.018

Hassan, R., Pike See, C., Sreenivasan, S., Mansor, S. M., Müller, C. P., and Hassan, Z. (2020). Mitragynine Attenuates Morphine Withdrawal Effects in Rats-A Comparison with Methadone and Buprenorphine. Front. Psychiatry 11, 11. doi:10.3389/fpsyt.2020.00411

Hassan, Z., Muzaimi, M., Navaratnam, V., Yusoff, N. H. M., Suhaimi, F. W., Vadivelu, R., et al. (2013). From Kratom to Mitragynine and its Derivatives: Physiological and Behavioural Effects Related to Use, Abuse, and Addiction. Neurosci. Biobehavioral Rev. 37, 138-151. doi:10.1016/j.neubiorev.2012.11.012

Hassan, Z., Suhaimi, F. W., Ramanathan, S., Ling, K.-H., Effendy, M. A., Müller, C. P., et al. (2019). Mitragynine (Kratom) Impairs Spatial Learning and Hippocampal Synaptic Transmission in Rats. J. Psychopharmacol. 33, 908-918. doi:10.1177/0269881119844186

He, Q., Su, G., Liu, K., Zhang, F., Jiang, Y., Gao, J., et al. (2017). Sex-specific Reference Intervals of Hematologic and Biochemical Analytes in SpragueDawley Rats Using the Nonparametric Rank Percentile Method. PLoS One 12, e0189837. doi:10.1371/journal.pone.0189837

Heinzerling, K. G. (2019). "Applying Best Practice Guidelines on Chronic Pain in Clinical Practice-Treating Patients Who Suffer from Pain and Addiction," in The Assessment and Treatment of Addiction. Editors I Danovitch and L J Mooney (Elsevier), 137-156. doi:10.1016/b978-0-323-54856-4.00009-2

Hiranita, T., Leon, F., Felix, J. S., Restrepo, L. F., Reeves, M. E., Pennington, A. E., et al. (2019). The Effects of Mitragynine and Morphine on Schedule-Controlled Responding and Antinociception in Rats. Psychopharmacology 236, 2725-2734. doi:10.1007/s00213-019-05247-7

Houtmeyers, A., Duchateau, L., Grünewald, B., and Hermans, K. (2016). Reference Intervals for Biochemical Blood Variables, Packed Cell Volume, and Body Temperature in Pet Rats (Rattus norvegicus) Using point-of-care Testing. Vet. Clin. Pathol. 45, 669-679. doi:10.1111/vcp.12419

Jamadarkhana, S., and Gopal, S. (2010). Clonidine in Adults as a Sedative Agent in the Intensive Care Unit. J. Anaesthesiol Clin. Pharmacol. 26, 439-445. 
Jamil, M. F. A., Subki, M. F. M., Lan, T. M., Majid, M. I. A., and Adenan, M. I. (2013). The Effect of Mitragynine on cAMP Formation and mRNA Expression of Mu-Opioid Receptors Mediated by Chronic Morphine Treatment in SK-NSH Neuroblastoma Cell. J. Ethnopharmacology 148, 135-143. doi:10.1016/ j.jep. 2013.03 .078

Jansen, K. L. R., and Prast, C. J. (1988). Ethnopharmacology of Kratom and the Mitragyna Alkaloids. J. Ethnopharmacology 23, 115-119. doi:10.1016/03788741(88)90121-3

Karch, S. B., and Stephens, B. G. (2000). Toxicology and Pathology of Deaths Related to Methadone: Retrospective Review. West. J. Med. 172, 11-14. doi:10.1136/ewjm.172.1.11

Kariya, N., Shindoh, M., Nishi, S., Yukioka, H., and Asada, A. (1998). Oral Clonidine for Sedation and Analgesia in a Burn Patient. J. Clin. Anesth. 10, 514-517. doi:10.1016/S0952-8180(98)00068-3

Kleber, H. D. (2007). Pharmacologic Treatments for Opioid Dependence: Detoxification and Maintenance Options. Dialogues Clin. Neurosci. 9, 455-470.

Kreek, M. J. (1973). Medical Safety and Side Effects of Methadone in Tolerant Individuals. Jama 223, 665-668. doi:10.1001/jama.1973.03220060039009

Kruegel, A. C., Gassaway, M. M., Kapoor, A., Váradi, A., Majumdar, S., Filizola, M., et al. (2016). Synthetic and Receptor Signaling Explorations of theMitragynaAlkaloids: Mitragynine as an Atypical Molecular Framework for Opioid Receptor Modulators. J. Am. Chem. Soc. 138, 6754-6764. doi:10.1021/jacs.6b00360

Kruegel, A. C., and Grundmann, O. (2018). The Medicinal Chemistry and Neuropharmacology of Kratom: A Preliminary Discussion of a Promising Medicinal Plant and Analysis of its Potential for Abuse. Neuropharmacology 134, 108-120. doi:10.1016/j.neuropharm.2017.08.026

Kuehn, B. (2019). Kratom-related Deaths. Jama 321, 1966. doi:10.1001/ jama.2019.6339

Kuo, A., Wyse, B. D., Meutermans, W., and Smith, M. T. (2015). In Vivoprofiling of Seven Common Opioids for Antinociception, Constipation and Respiratory Depression: No Two Opioids Have the Same Profile. Br. J. Pharmacol. 172, 532-548. doi:10.1111/bph.12696

Lei, J., Butz, A., and Valentino, N. (2021). Management of Kratom Dependence with Buprenorphine/naloxone in a Veteran Population. Substance Abuse, 1-11. doi:10.1080/08897077.2021.1878086

Leong Bin Abdullah, M. F. I., Tan, K. L., Mohd Isa, S., Yusoff, N. S., Chear, N. J. Y., and Singh, D. (2020). Lipid Profile of Regular Kratom (Mitragyna Speciosa Korth.) Users in the Community Setting. PLoS One 15, e0234639, . doi:10.1371/ journal.pone. 0234639

Ling, W., and Compton, P. (2005). Recent Advances in the Treatment of Opiate Addiction. Clin. Neurosci. Res. 5, 161-167. doi:10.1016/j.cnr.2005.08.012

Lukas, G., Brindle, S. D., and Greengard, P. (1971). The Route of Absorption of Intraperitoneally Administered Compounds. J. Pharmacol. Exp. Ther. 178, 562-564.

Macko, E., Weisbach, J. A., and Douglas, B. (1972). Some Observations on the Pharmacology of Mitragynine. Arch. Int. Pharmacodyn Ther. 198, 145-161.

Matsumoto, K., Mizowaki, M., Suchitra, T., Murakami, Y., Takayama, H., Sakai, S.i., et al. (1996). Central Antinociceptive Effects of Mitragynine in Mice: Contribution of Descending Noradrenergic and Serotonergic Systems. Eur. J. Pharmacol. 317, 75-81. doi:10.1016/s0014-2999(96)00714-5

Matsumoto, K., Mizowaki, M., Suchitra, T., Takayama, H., Sakai, S.-i., Aimi, N., et al. (1996). Antinociceptive Action of Mitragynine in Mice: Evidence for the Involvement of Supraspinal Opioid Receptors. Life Sci. 59, 1149-1155. doi:10.1016/0024-3205(96)00432-8

Mattick, R. P., and Hall, W. (1996). Are Detoxification Programmes Effective?. The Lancet 347, 97-100. doi:10.5555/uri:pii:S014067369690215910.1016/s01406736(96)90215-9

Mattick, R. P., Kimber, J., Breen, C., and Davoli, M. (2008). Buprenorphine Maintenance versus Placebo or Methadone Maintenance for Opioid Dependence. Cochrane Database Syst. Rev.. doi:10.1002/14651858.CD002207.pub3

McCormick, G. Y., White, W. J., Zagon, I. S., and Lang, C. M. (1984). Effects of Diazepam on Arterial Blood Gas Concentrations and pH of Adult Rats Acutely and Chronically Exposed to Methadone. J. Pharmacol. Exp. Ther. 230, 353-359.

McLaughlin, C. R., and Dewey, W. L. (1994). A Comparison of the Antinociceptive Effects of Opioid Agonists in Neonatal and Adult Rats in Phasic and Tonic Nociceptive Tests. Pharmacol. Biochem. Behav. 49, 1017-1023. doi:10.1016/ 0091-3057(94)90258-5
Meader, N. (2010). A Comparison of Methadone, Buprenorphine and Alpha2 Adrenergic Agonists for Opioid Detoxification: A Mixed Treatment Comparison Meta-Analysis. Drug and Alcohol Dependence 108, 110-114. doi:10.1016/j.drugalcdep.2009.12.008

Moayeri, A., Azimi, M., Karimi, E., Aidy, A., and Abbasi, N. (2018). Attenuation of Morphine Withdrawal Syndrome by Prosopis Farcta Extract and its Bioactive Component Luteolin in Comparison with Clonidine in Rats. Med. Sci. Monit. Basic Res. 24, 151-158. doi:10.12659/MSMBR.909930

Morgan, D., Cook, C. D., and Picker, M. J. (1999). Sensitivity to the Discriminative Stimulus and Antinociceptive Effects of Mu Opioids: Role of Strain of Rat, Stimulus Intensity, and Intrinsic Efficacy at the $\mathrm{Mu}$ Opioid Receptor. J. Pharmacol. Exp. Ther. 289, 965-975.

Müller, C. P. (2020). Drug Instrumentalization. Behav. Brain Res. 390, 112672. doi:10.1016/j.bbr.2020.112672

Müller, E., Hillemacher, T., and Müller, C. P. (2020). Kratom Instrumentalization for Severe Pain Self-Treatment Resulting in Addiction - A Case Report of Acute and Chronic Subjective Effects. Heliyon 6, e04507. doi:10.1016/ j.heliyon.2020.e04507

Müller, E., Hillemacher, T., and Müller, C. P. (2021). Kratom Use for Depression/ anxiety Self-Management: Challenges during the COVID-19 Pandemic - A Case Report. Heliyon 7, e07039. doi:10.1016/j.heliyon.2021.e07039

Neerman, M. F., Frost, R. E., and Deking, J. (2013). A Drug Fatality Involving Kratom. J. Forensic Sci. 58, S278-S279. doi:10.1111/1556-4029.12009

Nugraheni, P. W., Rahmawati, F., Mahdi, C., and Prasetyawan, S. (2017). Green tea Extract (Camellia Sinensis L.) Effects on Uric Acid Levels on Hyperuricemia Rats (Rattus norvegicus). JPACR 6, 9. doi:10.21776/ub.jpacr.2017.006.03.355

Obeng, S., Kamble, S. H., Reeves, M. E., Restrepo, L. F., Patel, A., Behnke, M., et al. (2020). Investigation of the Adrenergic and Opioid Binding Affinities, Metabolic Stability, Plasma Protein Binding Properties, and Functional Effects of Selected Indole-Based Kratom Alkaloids. J. Med. Chem. 63, 433-439. doi:10.1021/acs.jmedchem.9b01465

Peng, L., Yang, J., Lu, X., Okada, T., Kondo, T., Ruan, C., et al. (2004). Effects of Biological Variations on Platelet Count in Healthy Subjects in China. Thromb. Haemost. 91, 367-372. doi:10.1160/th03-05-0276

Petterino, C., and Argentino-Storino, A. (2006). Clinical Chemistry and Haematology Historical Data in Control Sprague-Dawley Rats from Preclinical Toxicity Studies. Exp. Toxicologic Pathol. 57, 213-219. doi:10.1016/ j.etp.2005.10.002

Prozialeck, W. C., Jivan, J. K., and Andurkar, S. V. (2012). Pharmacology of Kratom: An Emerging Botanical Agent with Stimulant, Analgesic and Opioidlike Effects. J. Am. Osteopath Assoc. 112, 792-799.

Prozialeck, W. C. (2016). Update on the Pharmacology and Legal Status of Kratom. J. Am. Osteopath Assoc. 116, 802-809. doi:10.7556/jaoa.2016.156

Radke, J. B., Owen, K. P., Sutter, M. E., Ford, J. B., and Albertson, T. E. (2014). The Effects of Opioids on the Lung. Clinic Rev. Allerg Immunol. 46, 54-64. doi:10.1007/s12016-013-8373-z

Raffa, R. B. (2015). Kratom and Other Mitragynines: The Chemistry and Pharmacology of Opioids from a Non-opium Source. CRC Press, Taylor \& Francis.

Rahman, S., Ali Khan, R., and Kumar, A. (2002). Experimental Study of the Morphine De-addiction Properties of Delphinium Denudatum Wall. BMC Complement. Altern. Med. 2, 6. doi:10.1186/1472-6882-2-6

Ramsey, P. H. (1993). "Multiple Comparisons of Independent Means," in Applied Analysis of Variance in Behavioral Science. Editor L Edwards (New York: Marcel Dekker), 25-61.

Rostaing, S., Bonnet, F., Levron, J. C., Vodinh, J., Pluskwa, F., and Saada, M. M. D. (1991). Effect of Epidural Clonidine on Analgesia and Pharmacokinetics of Epidural Fentanyl in Postoperative Patients. Anesthesiology 75, 420-425. doi:10.1097/00000542-199109000-00007

Sabetghadam, A., Ramanathan, S., Sasidharan, S., and Mansor, S. M. (2013). Subchronic Exposure to Mitragynine, the Principal Alkaloid of Mitragyna Speciosa, in Rats. J. Ethnopharmacology 146, 815-823. doi:10.1016/j.jep.2013.02.008

Saingam, D., Assanangkornchai, S., Geater, A. F., and Lerkiatbundit, S. (2016). Factor Analytical Investigation of Krathom (Mitragyna speciosaKorth.) Withdrawal Syndrome in Thailand. J. Psychoactive Drugs 48, 76-85. doi:10.1080/02791072.2016.1156791

Santiago, T. V., and Edelman, N. H. (1985). Opioids and Breathing. J. Appl. Physiol. 59, 1675-1685. doi:10.1152/jappl.1985.59.6.1675 
Schaap, M. W. H., Uilenreef, J. J., Mitsogiannis, M. D., van 't Klooster, J. G., Arndt, S. S., and Hellebrekers, L. J. (2012). Optimizing the Dosing Interval of Buprenorphine in a Multimodal Postoperative Analgesic Strategy in the Rat: Minimizing Side-Effects without Affecting Weight Gain and Food Intake. Lab. Anim. 46, 287-292. doi:10.1258/la.2012.012058

Shamima, A. R., Fakurazi, S., Hidayat, M. T., Hairuszah, I., Moklas, M. A. M., and Arulselvan, P. (2012). Antinociceptive Action of Isolated Mitragynine from Mitragyna Speciosa through Activation of Opioid Receptor System. Ijms 13, 11427-11442. doi:10.3390/ijms130911427

Singh, D., Müller, C. P., and Vicknasingam, B. K. (2014). Kratom (Mitragyna Speciosa) Dependence, Withdrawal Symptoms and Craving in Regular Users. Drug and Alcohol Dependence 139, 132-137. doi:10.1016/j.drugalcdep.2014.03.017

Singh, D., Narayanan, S., Müller, C. P., Swogger, M. T., Rahim, A. A., Leong Bin Abdullah, M. F. I., et al. (2018). Severity of Kratom (Mitragyna Speciosa Korth.) Psychological Withdrawal Symptoms. J. Psychoactive Drugs 50, 445-450. doi:10.1080/02791072.2018.1511879

Singh, D., Narayanan, S., Vicknasingam, B. K., Prozialeck, W. C., Ramanathan, S., Zainal, H., et al. (2018). Severity of Pain and Sleep Problems during Kratom (Mitragyna speciosaKorth.) Cessation Among Regular Kratom Users. J. Psychoactive Drugs 50, 266-274. doi:10.1080/ 02791072.2018.1443234

Sireesha, J., Jayasree, T., lakshmi, K. S., and Vijayal, K. (2015). Study of Onset and Duration of Sedative Effect of Clonidine with Various Routes of Administration in Wistar Albino Rats. Natl. J. Med. Res. Yoga Sci. 1, 15-18.

Stanciu, C. N., Gnanasegaram, S. A., Ahmed, S., and Penders, T. (2019). Kratom Withdrawal: A Systematic Review with Case Series. J. Psychoactive Drugs 51, 12-18. doi:10.1080/02791072.2018.1562133

Suwanlert, S. (1975). A Study of Kratom Eaters in Thailand. Bull. Narc 27, 21-27.

Swogger, M. T., and Walsh, Z. (2018). Kratom Use and Mental Health: A Systematic Review. Drug and Alcohol Dependence 183, 134-140. doi:10.1016/j.drugalcdep.2017.10.012

Takayama, H. (2004). Chemistry and Pharmacology of Analgesic Indole Alkaloids from the Rubiaceous Plant, Mitragyna Speciosa. Chem. Pharm. Bull. 52, 916-928. doi:10.1248/cpb.52.916

Takayama, H., Kurihara, M., Kitajima, M., Said, I. M., and Aimi, N. (1998). New Indole Alkaloids from the Leaves of Malaysian Mitragyna Speciosa. Tetrahedron 54, 8433-8440. doi:10.1016/S0040-4020(98)00464-5

Tierney, C., Nadaud, D., Koenig-Berard, E., and Stinus, L. (1988). Effects of Two Alpha2 Agonists, Rilmenidine and Clonidine, on the Morphine Withdrawal Syndrome and Their Potential Addictive Properties in Rats. Am. J. Cardiol. 61, D35-D38. doi:10.1016/0002-9149(88)90462-6

Tsuchiya, S., Miyashita, S., Yamamoto, M., Horie, S., Sakai, S.-I., Aimi, N., et al. (2002). Effect of Mitragynine, Derived from Thai Folk Medicine, on Gastric Acid Secretion through Opioid Receptor in Anesthetized Rats. Eur. J. Pharmacol. 443, 185-188. doi:10.1016/s0014-2999(02)01588-1

Turner, P. V., Brabb, T., Pekow, C., and Vasbinder, M. A. (2011). Administration of Substances to Laboratory Animals: Routes of Administration and Factors to Consider. J. Am. Assoc. Lab. Anim. Sci. 50, 600-613.

Utar, Z., Majid, M. I. A., Adenan, M. I., Jamil, M. F. A., and Lan, T. M. (2011). Mitragynine Inhibits the COX-2 mRNA Expression and Prostaglandin E2
Production Induced by Lipopolysaccharide in RAW264.7 Macrophage Cells. J. Ethnopharmacology 136, 75-82. doi:10.1016/j.jep.2011.04.011

Váradi, A., Marrone, G. F., Palmer, T. C., Narayan, A., Szabó, M. R., Le Rouzic, V., et al. (2016). Mitragynine/Corynantheidine Pseudoindoxyls as Opioid Analgesics with Mu Agonism and Delta Antagonism, Which Do Not Recruit $\beta$-Arrestin-2. J. Med. Chem. 59, 8381-8397. doi:10.1021/acs.jmedchem.6b00748

Vicknasingam, B., Narayanan, S., Beng, G. T., and Mansor, S. M. (2010). The Informal Use of Ketum (Mitragyna Speciosa) for Opioid Withdrawal in the Northern States of Peninsular Malaysia and Implications for Drug Substitution Therapy. Int. J. Drug Pol. 21, 283-288. doi:10.1016/j.drugpo.2009.12.003

Washton, A. M., and Resnick, R. B. (1981). Clonidine in Opiate Withdrawal: Review and Appraisal of Clinical Findings. Pharmacotherapy 1, 140-146. doi:10.1002/j.1875-9114.1981.tb03561.x

Watanabe, K., Yano, S., Horie, S., and Yamamoto, L. T. (1997). Inhibitory Effect of Mitragynine, an Alkaloid with Analgesic Effect from Thai Medicinal Plant Mitragyna Speciosa, on Electrically Stimulated Contraction of Isolated guineapig Ileum through the Opioid Receptor. Life Sci. 60, 933-942. doi:10.1016/ s0024-3205(97)00023-4

Weiss, S. T., and Douglas, H. E. (2021). Treatment of Kratom Withdrawal and Dependence with Buprenorphine/naloxone: A Case Series and Systematic Literature Review. J. Addict. Med. 15, 167-172. doi:10.1097/ adm. 0000000000000721

White, J. M., and Irvine, R. J. (1999). Mechanisms of Fatal Opioid Overdose. Addiction 94, 961-972. doi:10.1046/j.1360-0443.1999.9479612.x

Yearsley, C.. Kratom: Medicine or Menace? HerbalGram [Internet]. (2016); (112): [46-59 pp.]. Available from: http://cms.herbalgram.org/herbalgram/issue112/ hg112-feat-kratom-med-men.html?ts=1610423962\&signature $=7$ fbe $777 \mathrm{~d} 035$ bc0bb7dc5976b69c5cc04. (Accessed May 29, 2019).

Yusoff, N. H. M., Mansor, S. M., Müller, C. P., and Hassan, Z. (2017). Opioid Receptors Mediate the Acquisition, but Not the Expression of MitragynineInduced Conditioned Place Preference in Rats. Behav. Brain Res. 332, 1-6. doi:10.1016/j.bbr.2017.05.059

Yusoff, N. H. M., Suhaimi, F. W., Vadivelu, R. K., Hassan, Z., Rümler, A., Rotter, A., et al. (2016). Abuse Potential and Adverse Cognitive Effects of Mitragynine (Kratom). Addict. Biol. 21, 98-110. doi:10.1111/adb.12185

Ziaaddini, H., Nasirian, M., and Nakhaee, N. (2012). Comparison of the Efficacy of Buprenorphine and Clonidine in Detoxification of Opioid-Dependents. Addict. Health 4, 79-86.

Conflict of Interest: The authors declare that the research was conducted in the absence of any commercial or financial relationships that could be construed as a potential conflict of interest.

Copyright () 2021 Hassan, Sreenivasan, Müller and Hassan. This is an open-access article distributed under the terms of the Creative Commons Attribution License (CC $B Y)$. The use, distribution or reproduction in other forums is permitted, provided the original author(s) and the copyright owner(s) are credited and that the original publication in this journal is cited, in accordance with accepted academic practice. No use, distribution or reproduction is permitted which does not comply with these terms. 